\title{
Regional pulmonary function in patients with mitral stenosis in relation to haemodynamic data
}

\author{
P. Jebavý, I. Runczik, A. Oppelt, J. Tilsch, V. Stanĕk, and J. Widimský \\ From the Institute of Cardiovascular Research, and the Research Institute for Medical \\ Use of Radioisotopes, Budějovická 800, Prague-Krť, Czechoslovakia
}

Central haemodynamics in 23 patients with mitral stenosis and 7 control subjects were compared with the results of regional lung perfusion studied by ${ }^{133} \mathrm{Xe}$, pulmonary scintigraphy with ${ }^{99} \mathrm{mTc}$ labelled macro-aggregates of albumin, and regional ventilation by ${ }^{133} \mathrm{Xe}$.

$A$ close correlation was found between both methods assessing regional pulmonary perfusion, i.e. pulmonary scintigraphy and ${ }^{133} \mathrm{Xe}$.

The results show that lower lung zones, when compared with upper zones, have both worse perfusion and worse ventilation.

The changed distribution of perfusion and the changed distribution of ventilation correlated significantly with central haemodynamics in these patients. The ventilation gradient can be a valuable diagnostic tool for evaluating the severity of mitral stenosis, especially in long and repeated studies, due to its simplicity for the patient.

It is generally known that patients with mitral stenosis have a vertical distribution of pulmonary perfusion different from that of control subjects. In seated normal subjects, the lower pulmonary zones are better perfused than the upper ones (West and Dollery, 1960; West, 1962; Ball et al., 1962; Widimský et al., 1965; Bake, Bjure, and Widimský, 1968), whereas in seated patients with mitral stenosis, the upper pulmonary zones are better perfused (Dollery and West, 1960; West, Dollery, and Heard, 1965; Dawson, Kaneko, and McGregor, 1965). The change in the perfusion gradient may have a connexion with the degree of the mitral stenosis, and to a certain extent it could be related to the haemodynamic severity of the lesion, as shown by Dawson et al. (1965), who used the radioactive ${ }^{133} \mathrm{Xe}$ method, and by Friedman and Braunwald (1966), Steiner and Quinn (1968), and Kunieda (1967), who used lung scintigraphy with ${ }^{131} \mathrm{I}$-labelled albumin macro-aggregates.

The purpose of this work was (I) to study the distribution of ventilation in mitral stenosis patients; (2) to evaluate the possibility of using the change in the distribution of ventilation for assessing the severity of mitral stenosis; and (3) to compare the distribution of perfusion studied by means of ${ }^{133} \mathrm{Xe}$ with lung scanning technique.

Received 17 November 1969.
Both the distribution of ventilation and perfusion studied by ${ }^{133} \mathrm{Xe}$ was determined with the simplest radioisotope apparatus, which is available in nearly every radioiscitope diagnostic unit.

\section{Methods}

Our series comprised 23 patients with mitral stenosis and 7 control subjects. I9 patients with mitral stenosis and 6 control subjects were examined for regional pulmonary perfusion with ${ }^{133} \mathrm{Xe}$. Thirteen of the total number of mitral stenosis patients and one control subject were examined for regional pulmonary ventilation with ${ }^{133} \mathrm{Xe}$. Scintigraphic examinations of regional pulmonary perfusion were performed in II patients with mitral stenosis and 3 control subjects. All patients had a complete haemodynamic examination within one week of the isotope tests.

Haemodynamic data were obtained in recumbent subjects by catheterization of the left and right heart. The pressures in the pulmonary artery, in the wedged position or in the left atrium, were measured by electromanometers Elema, and recorded by the direct-writing Cardirex (Siemens) recorder. For the left atrial pressure, values of pressures in the left atrium obtained by transseptal catheterization or pressures in the wedged position were used. The cardiac output was measured by dye dilution method. Indocyanine green was injected into the main branch of the pulmonary artery in amounts 
3.5-6.0 mg. of a $5 \mathrm{mg} . / \mathrm{ml}$. solution for each injection. Blood was sucked through a densitometer at constant rate by means of a pump from a catheter with the tip situated just below the aortic arch. The suction rates were $1 \cdot 2 \mathrm{ml}$. $/ \mathrm{sec}$. The densitometer and recording device were the Cambridge Dye Dilution Outfit Mark II. The cardiac output was calculated according to the method of Stuart-Hamilton (Hamilton et al., I932; Hamilton, I962).

Pulmonary vascular resistance was calculated from the formula:

$$
\mathrm{PVR}=\frac{\mathbf{P}_{\mathrm{PA}}-\mathbf{P}_{\mathrm{LA}}(\mathrm{PCV})}{\mathrm{CO}} \mathrm{mm} . \mathrm{Hg} / \mathrm{l} \text {. per min. }
$$

Regional pulmonary perfusion was assessed with the aid of radioactive ${ }^{133} \mathrm{Xe}$ and the standard two detectors diagnostic unit, as used in renography. Scintillation detectors with crystals $5 \mathrm{~cm}$. in diameter were equipped with collimators with a relatively large visual field. The collimators were $16 \mathrm{~cm}$. long, with an external orifice of $10 \mathrm{~cm}$. The spectrometer windows were set on the $8 \mathrm{I} \mathrm{keV}$ photopeak.

The detectors were attached to the posterior chest wall of sitting patients, in such a way that one of them was measuring the radiation coming from the upper left lung field and the other from the lower right field. About $100-200 \mu \mathrm{Ci}$ of ${ }^{133} \mathrm{Xe}$ in saline were injected into the cubital vein while the subject held his breath at total lung capacity with the glottis opened. With the subject holding his breath the counting rate measured by the extrathoracic detectors rises until it reaches a plateau. Breath holding is controlled by another probe placed in the expiratory tube or by a spirometer. After reaching the plateau the patient breathes into the closed circuit of the spirometer with a $\mathrm{CO}_{2}$ absorber until an equilibrium of ${ }^{133} \mathrm{Xe}$ concentration between the spirometer and lungs is reached. Afterwards the patient holds his breath again at total lung capacity. The heights of the curves enable correction of the ratio of the upper and lower lung field perfusion to alveolar volume from which the radiation is detected according to the formula used in our laboratory (Oppelt et al., 1966).

$$
\begin{aligned}
& \mathrm{U} / \mathrm{L}=\frac{\text { height of the upper zone primary plateau }}{\text { height of the lower zone primary plateau }} \\
& \text { height of the lower zone plateau after } \\
& \times \frac{\text { rebreathing }}{\text { height of the upper zone plateau after }} \text {. }
\end{aligned}
$$

This method was compared in a group of 9 subjects with a scintigraphic method using macroaggregates of albumin labelled with ${ }^{99 \mathrm{~m}} \mathrm{Tc}$. These were administered in the amount of $200-500 \mu \mathrm{Ci}$ in a sitting position.

Anterior scintigrams were then obtained in the supine position using a Siemens Nucleograph with a crystal $4.5 \mathrm{~cm}$. in diameter and a sevenhole ro $\mathrm{cm}$. long collimator with a focal length of ro cm. The patient's chest was supported with a pillow in order to keep it in a horizontal position.

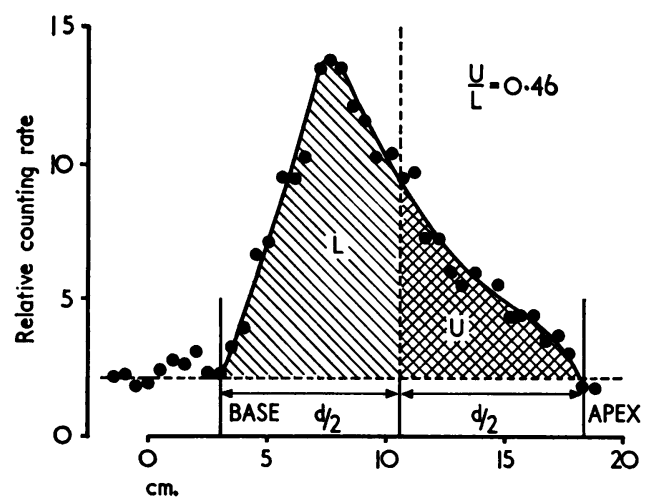

FIG. I The longitudinal profile of the counting rate of control subjects.

The counting rate was recorded by a strip chart recorder. Afterwards the maximum counting rates were selected on each line over the right lung scanned from side to side successively from the base to the apex. Then a longitudinal profile was arranged (Fig. I) for a control subject. The perfusion ratio U/L (MAA) of the upper and lower lung region was then evaluated as a ratio of surfaces $U$ and $L$, as seen in Fig. I.

The distribution of ventilation was estimated with the same two-probe unit as was used in studies of perfusion distribution and was placed in an identical manner.

Regional ventilation was estimated by calculating the half-time of washout curves after intravenous injection of ${ }^{133} \mathrm{Xe}$. This time ${ }^{133} \mathrm{Xe}$ in saline was injected during quiet breathing of the patients.

Ventilation gradient was calculated as a relation of half-time washout curves transferred on a semilogarithmic scale, defined from a straight line drawn between 90 and 50 per cent of their actual height (Oppelt et al., 1966) according to the following relation.

$$
\mathrm{V}(\mathrm{L} / \mathrm{U})=\frac{\operatorname{Tr} / 2 \text { (lower lung field) }}{\operatorname{Tr} / 2 \text { (upper lung field) }}
$$

In these figures ventilatory gradient greater than ' $I$ ' means that the half-time of the radioactivity washout curve is longer in the lower lung field as compared with the upper one. Therefore in our figures a ventilatory gradient greater than ' $I$ ' indicates better ventilation of the upper lung areas, basal areas being relatively hypoventilated. On the other hand, the basal areas are better ventilated than the upper ones in all cases where the gradient is lower than ' $I$ '.

This method measures the ventilation of perfused lung areas, and therefore it is not suitable for studies dealing with patients with chronic pulmonary diseases (e.g. pulmonary emphysema) where areas can be expected which are ventilated but underperfused. For clinical studies dealing with the distribution of ventilation in cardiac patients this method can be used. 
TABLE I Haemodynamic data and perfusion and ventilation data obtained by the ${ }^{133} \mathrm{Xe}$ method

\begin{tabular}{|c|c|c|c|c|c|c|c|c|}
\hline Initials & $\begin{array}{l}\text { Age } \\
(y r .)\end{array}$ & Sex & $\begin{array}{l}\text { Mean pulm. } \\
\text { art. pressure } \\
(\mathrm{mm} . \mathrm{Hg})\end{array}$ & $\begin{array}{l}\text { Mean left } \\
\text { atrial (wedge) } \\
(\mathrm{mm} . \mathrm{Hg})\end{array}$ & $\begin{array}{l}\text { Gradient } \\
\text { between } \\
\text { pulm. art. } \\
\text { and lt. atrium }\end{array}$ & $\begin{array}{l}\text { Cardiac } \\
\text { output }\end{array}$ & $\begin{array}{l}\text { Pulm. } \\
\text { arterial } \\
\text { resist. }\end{array}$ & $U / L{ }^{133} \mathrm{Xe} \quad V(L / U)$ \\
\hline
\end{tabular}

\begin{tabular}{|c|c|c|c|c|c|c|c|c|c|}
\hline \multicolumn{10}{|c|}{ Mitral stenosis } \\
\hline J.B. & 39 & $\mathbf{F}$ & I6 & 12 & 4 & $5 \cdot 3$ & 0.75 & 0.86 & 0.57 \\
\hline D.J. & 27 & $\mathbf{F}$ & 47 & 24 & 23 & $6 \cdot 0$ & 3.83 & $1 \cdot 33$ & 0.93 \\
\hline J.M. & 46 & $\mathrm{~F}$ & 44 & 26 & 18 & $7 \cdot 8$ & $2 \cdot 31$ & $\begin{array}{l}1 \\
I\end{array}$ & 0.69 \\
\hline M.K. & 42 & $\mathrm{~F}$ & 31 & 25 & 6 & $5 \cdot 6$ & $1 \cdot 07$ & 0.67 & 0.61 \\
\hline J.Z. & 43 & $\mathrm{~F}$ & 20 & 16 & 4 & $5 \cdot 2$ & 0.77 & 0.65 & 0.59 \\
\hline J.F. & 45 & $\mathbf{M}$ & 22 & 13 & 9 & $2 \cdot 7$ & $3 \cdot 33$ & 0.87 & - \\
\hline V.J. & 42 & $\mathbf{F}$ & 38 & 26 & 12 & $3 \cdot 4$ & 3.53 & 0.84 & 0.78 \\
\hline L.Č. & 44 & $\mathrm{~F}$ & 33 & 18 & 15 & $5 \cdot 1$ & 2.94 & 0.87 & 0.80 \\
\hline V.S. & 40 & $\mathbf{M}$ & 67 & 33 & 34 & $4^{\cdot I}$ & $8 \cdot 29$ & $I \cdot 12$ & $I \cdot I 6$ \\
\hline P.B. & 22 & $\mathbf{F}$ & 50 & 35 & 15 & $5 \cdot 1$ & 2.94 & I.67 & - \\
\hline R.S. & 36 & $F$ & 33 & 20 & 13 & 2.5 & $5 \cdot 20$ & $1 \cdot 72$ & 0.95 \\
\hline M.H. & 40 & $\mathbf{M}$ & 71 & 26 & 45 & $4 \cdot 7$ & 9.57 & I. 41 & $I \cdot 33$ \\
\hline K.S. & 35 & $\mathbf{M}$ & 53 & 26 & 27 & $3 \cdot 2$ & $8 \cdot 44$ & $1 \cdot 69$ & $I \cdot 15$ \\
\hline M.D. & 22 & $\mathbf{F}$ & 36 & 25 & II & $4 \cdot 0$ & $2 \cdot 75$ & $1 \cdot 35$ & 1.00 \\
\hline M.D. & 45 & $\mathbf{M}$ & 30 & 24 & 6 & $6 \cdot 7$ & 0.90 & $0.8 \mathrm{I}$ & - \\
\hline A.N. & 53 & $F$ & 33 & 12 & 21 & $6 \cdot 3$ & $3 \cdot 33$ & 0.87 & - \\
\hline R.B. & 23 & $\mathbf{F}$ & 38 & 29 & 9 & 6.0 & $1 \cdot 50$ & $I \cdot 72$ & - \\
\hline Z.J. & 35 & $\mathbf{M}$ & 50 & 25 & 25 & $5 \cdot 1$ & 4.90 & $1 \cdot 28$ & - \\
\hline B.C. & 40 & $\mathbf{M}$ & 50 & 32 & 18 & - & - & $1 \cdot 12$ & $1 \cdot \infty$ \\
\hline \multicolumn{10}{|c|}{ Controls } \\
\hline J.J. & 30 & $\mathbf{F}$ & 18 & I0 & 8 & 6.6 & $I \cdot 2 I$ & 0.57 & - \\
\hline J.P. & 27 & $M$ & 13 & 8 & 5 & $10 \cdot 3$ & 0.49 & 0.35 & - \\
\hline B.B. & 19 & $M$ & 18 & II & 7 & $12 \cdot 4$ & 0.56 & 0.38 & 0.43 \\
\hline M.P. & 39 & $M$ & I6 & 8 & 8 & $8 \cdot 2$ & 0.98 & 0.47 & - \\
\hline J.D. & 18 & $\mathbf{M}$ & 15 & 9 & 6 & $9 \cdot 7$ & 0.62 & 0.37 & - \\
\hline J.P. & 25 & $M$ & 15 & 8 & 7 & II 0 & 0.64 & 0.53 & - \\
\hline
\end{tabular}

\section{Results}

Table I gives haemodynamic data together with values of perfusion and ventilation gradients, obtained by the ${ }^{133} \mathrm{Xe}$ method. Table 2 gives values of perfusion gradients obtained by the scintigraphic method. Table 3 gives values of perfusion gradients obtained in a group of 9 subjects both by the scintigraphic and the ${ }^{133} \mathrm{Xe}$ methods.

The values of the perfusion gradient, obtained by either method, are always lower in healthy subjects (except a single control subject) than in patients with mitral stenosis. The perfusion gradient averages 0.49 (0.35$0.66)$ in normal subjects, and $\mathrm{I} \cdot 10$ (0.63$I \cdot 72$ ) in patients with mitral stenosis. The difference is statistically significant $(p<$ 0.001 ).

The values of regional perfusion obtained by both the scintigraphic and the ${ }^{133} \mathrm{Xe}$ methods show a close correlation with a high correlation coefficient $(r=+0.906)$, at the significance level $\mathrm{p}<0.00 \mathrm{I}$, as shown in Fig. 2.
TABLE 2 Haemodynamic data and perfusion gradient volumes obtained by lung scintigraphy$U / L(M A A)$

\begin{tabular}{|c|c|c|c|c|c|c|c|c|}
\hline Initials & $\begin{array}{l}\text { Age } \\
(y r .)\end{array}$ & Sex & $\begin{array}{l}\text { Mean } \\
\text { pulm. art. } \\
\text { pressure } \\
\text { (mm. } \mathrm{Hg} \text { ) }\end{array}$ & $\begin{array}{l}\text { Mean left } \\
\text { atrial } \\
\text { wedge }\end{array}$ & $\Delta P$ & $\mathrm{CO}$ & $\begin{array}{l}\text { Pulm. } \\
\text { arterial } \\
\text { resist. }\end{array}$ & $U / L$ \\
\hline
\end{tabular}

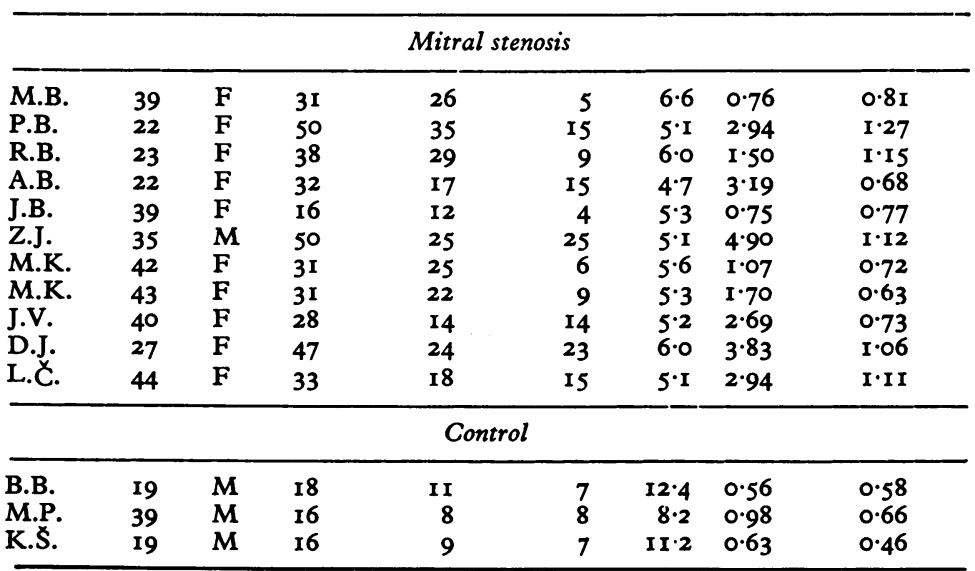

$\Delta \mathbf{P}=$ gradient between pulmonary artery and left atrium. $\mathrm{CO}=$ cardiac output. 
TABLE 3 Comparison of perfusion gradient values obtained by lung scintigraphy and by ${ }^{133} \mathrm{Xe}$

\begin{tabular}{|c|c|c|c|c|}
\hline Initials & $\begin{array}{l}\text { Age } \\
(y r .)\end{array}$ & Sex & $U ! L(X e)$ & $\begin{array}{l}U / L \\
(M A A)\end{array}$ \\
\hline \multicolumn{5}{|c|}{ Mitral stenosis } \\
\hline Z.J. & 35 & $\mathbf{M}$ & $I \cdot 28$ & $I \cdot 12$ \\
\hline R.B. & 23 & $\mathrm{~F}$ & $I \cdot 72$ & $1 \cdot 15$ \\
\hline J.B. & 39 & $\mathbf{F}$ & 0.86 & 0.77 \\
\hline D.J. & 27 & F & $I \cdot 33$ & I.06 \\
\hline M.K. & 42 & $\mathrm{~F}$ & 0.67 & 0.72 \\
\hline L.Č. & 44 & F & 0.87 & $\mathbf{I} \cdot \mathbf{I} \mathbf{I}$ \\
\hline P.B. & 22 & $\mathrm{~F}$ & $\mathrm{I} \cdot 67$ & $\mathrm{I} \cdot \mathbf{2 7}$ \\
\hline \multicolumn{5}{|c|}{ Controls } \\
\hline B.B. & 19 & $\mathbf{M}$ & 0.38 & 0.58 \\
\hline M.P. & 39 & $\mathbf{M}$ & 0.47 & 0.66 \\
\hline
\end{tabular}

The dependence of the perfusion gradient on the left atrial pressure (or on the wedge pressure), and on the pulmonary arterial pressure (established in 19 patients with mitral stenosis and 6 control subjects), is statistically significant $(r=+0.75 \mathrm{I}$ for the left atrial pressure, and $r=+0.735$ for the pulmonary arterial pressure, both at the significance level $\mathrm{p}<0.00 \mathrm{I}$ ).

Analogous statistically significant correlations were found by the scintigraphic method in I I patients with mitral stenosis and 3 control subjects for the left atrial pressure $(r=+0.745, p<0.01)$, and for the pulmonary arterial pressure $(r=+0.826, p<0.001)$, as is seen from Fig. 3.

We also found a positive correlation of the perfusion gradient with the pressure gradient

FIG. 2 Correlation between values of perfusion gradients, obtained respectively by method using ${ }^{133} \mathrm{Xe}(U / L \mathrm{Xe})$ and pulmonary scintigraphy (U/L MAA).

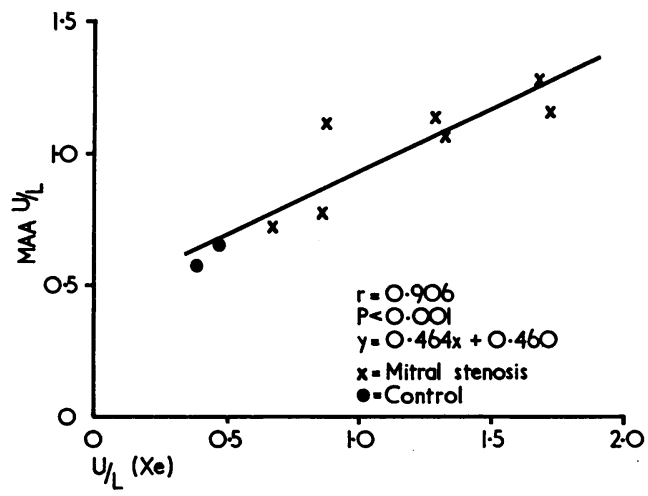

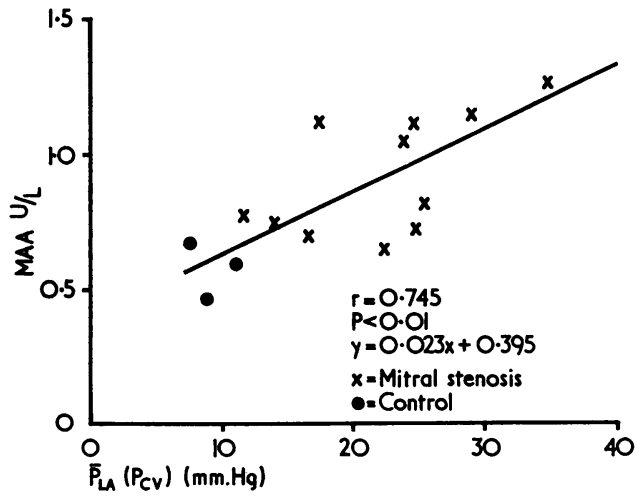

FIG. 3 Correlation between left atrial or wedge pressure and perfusion gradient obtained by lung scintigraphy.

between the pulmonary artery and the left atrium. This correlation, though not too close, is statistically significant for both the scintigraphic $(r=+0.584, p<0.05)$ and the ${ }^{133} \mathrm{Xe}$ methods $(\mathrm{r}=+0.552, \mathrm{p}<0.0 \mathrm{r})$.

If, in mitral stenosis, the left atrial pressure or the pulmonary arterial pressure, but also the pressure gradient between the pulmonary artery and the left atrium, increase, then also the pathological distribution of ventilation increases so that the higher the pulmonary arterial pressure $(r=+0.882$, $\mathrm{p}<0.00 \mathrm{r}$ ) (Fig. 4), the left atrial pressure $(r=+0.704, p<0.01)$ (Fig. 5), or the gradient between these pressures $(r=+0.872, p<$ 0.001 ) (Fig. 6), the poorer the ventilation of the lower lung zones when compared to the upper zones.

The same relationships are found if pulmonary vascular resistance values are used instead of pressure values.

Fig. 7 shows the correlation between the

FIG. 4 Correlation between pulmonary arterial pressure and ventilation gradient.

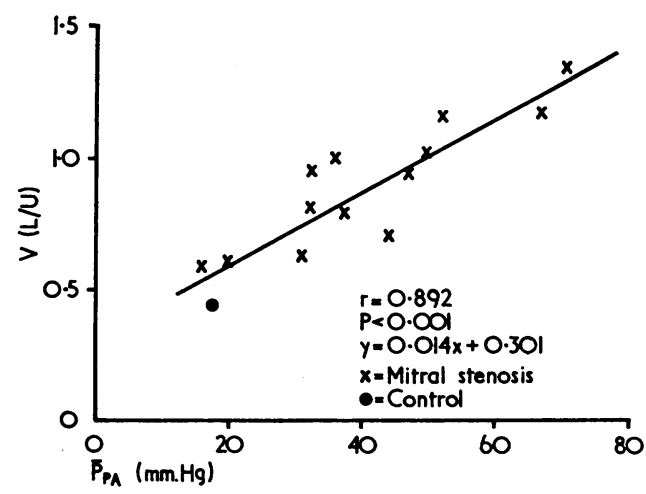




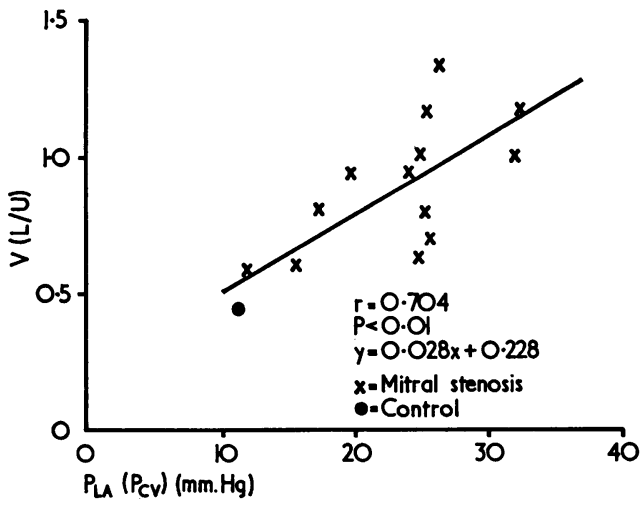

FIG. 5 Correlation between left atrial pressure and ventilation gradient.

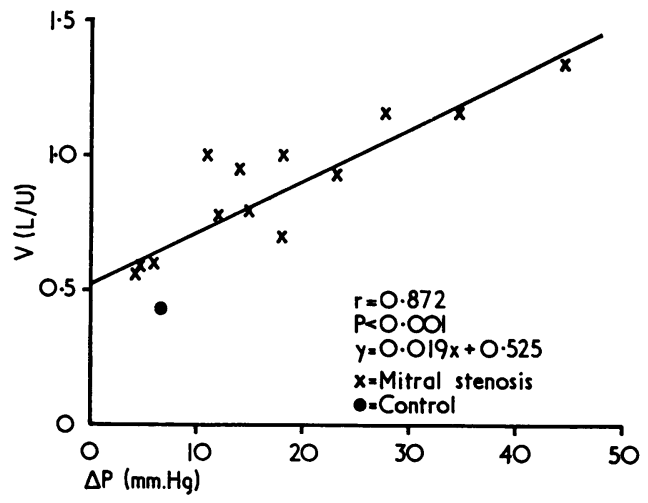

FIG. 6 Correlation between pressure difference in pulmonary artery - left atrium and ventilation gradient.

FIG. 7 Correlation between magnitudes of perfusion gradient $U / L{ }^{133} \mathrm{Xe}$ and of ventilation gradient $V(L / U)$.

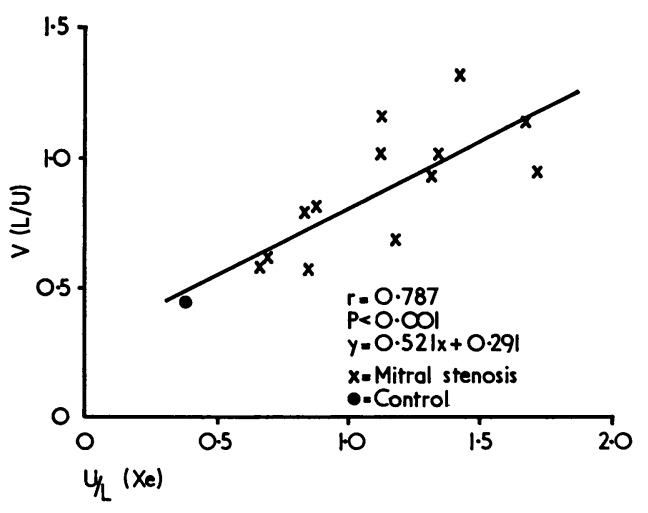

perfusion gradient (plotted on the $\mathrm{x}$ axis) and the ventilation gradient ( $y$ axis). This correlation is also statistically significant $(r=+0.787$, $\mathrm{p}<0 \cdot 00 \mathrm{I}$ ).

\section{Discussion}

The results obtained by assessing regional pulmonary perfusion by both methods described above indicate that each of them may serve for classification of mitral stenosis according to the haemodynamic significance, despite the great variations due to imperfections in the methods.

It must be considered, however, that the perfusion gradient may change under any condition connected with pulmonary hypertension or increased pulmonary blood flow, e.g. primary pulmonary hypertension (Steiner and Quinn, 1968), congenital heart disease involving left-to-right shunts (Dollery et al., 196I), and left heart insufficiency (Kunieda, 1967). Under all these conditions, however, in contrast to mitral stenosis, the gradient may only be brought to the level but never reversed.

Moreover, it must be stressed that pathological changes and processes occurring in the lung parenchyma, e.g. cysts, tumours, pneumonia, emphysema, pulmonary infarction, or embolism, as well as extrapulmonary pathological states, such as pleural exudate, may change the distribution of the blood flow. In any case, attention must be paid to the clinical picture, and particularly to the $x$-ray examination, and possibly to the lung scan.

Each of both methodical procedures for assessing the regional pulmonary perfusion, discussed in this contribution, has certain advantages and disadvantages. The radioactive xenon method is more exacting, demanding co-operation of the patient, and particularly requiring that he holds his breath long enough. On the other hand, the advantage is that the injection can be repeated several times, and that a correction to the alveolar volume can be made. The scintigraphic method is less exacting for the patient but in the procedure described no correction for the volume detected is made.

In one paper, Dawson et al. (1965) assessed the regional pulmonary ventilation in mitral stenosis, but did not find any connexion between the distribution of ventilation and the changed distribution of perfusion; they found only a poor correlation between the distribution of ventilation and haemodynamic data. The discrepancy between his and our data might be due to the difference in methods 
used (Dawson has been using single breath techniques), but also the differences in clinical material could be responsible.

On the basis of our results, obtained in the assessments of regional ventilation, it might be concluded that the assessments of both regional perfusion and regional ventilation may serve for practically judging the haemodynamic significance of mitral stenosis. Both procedures are feasible even by simple methods and techniques, as we endeavoured to show in our communication. With regard to its acceptability for the patient and to easy ventilation, we consider the assessment of regional ventilation to be very advantageous and to be recommended as a suitable supplementary examination of patients with mitral stenosis.

In our sample of patients we found no correlation either between the perfusion or the ventilation gradient and the clinical state of mitral stenosis, evaluated according to the classification of the New York Heart Association, or the patient's history of the duration of his dyspnoea.

It is theoretically conceivable that the assessment of the regional ventilation, as we perform it, involves a potential source of error, represented by a low cardiac output, which slows down the flow of the radioactive substance into the lungs. This effect is likely to play a greater role in those pulmonary zones that are better ventilated, yielding a false picture of the real ventilation and thus apparently bringing the value of the ventilation gradient towards unity. It is inconceivable, however, that the ventilation gradient could be reversed because of this error.

In addition, the fact that we found no correlation between the value of the cardiac output and the ventilation gradient $\mathrm{V}(\mathrm{L} / \mathrm{U})$ disproves the possibility that a low cardiac output might be a serious source of error in measuring the regional ventilation.

The magnitude of the time constant of the rate-meter cannot represent a source of measuring error with regard to the range of half times we have found.

The volume of blood present between the injection site of ${ }^{133} \mathrm{X}$ and the pulmonary artery serves as a mixing space for the radioactive substance and thus influences its attenuation, while, in turn, the supply rate of the radioactive substance into the pulmonary artery is governed. Differences in the magnitudes of this blood volume can represent a source of error in measurements of the regional ventilation by our method. Our methodical arrangement prevents the estimation of the magnitude of this potential error.
The same conclusion is valid again in that the ventilation gradient may be brought level, but never reversed, in consequence of this error.

Admittedly, haemodynamic examinations will retain their fundamental value for assessing the significance of mitral stenosis. Nevertheless, radioisotope methods may be accepted as useful supplementary means of examination, particularly because of their simplicity and acceptability for the patient. They can be valuable especially in long-term and repeated studies, and can indicate the progression of the disease, and, in appropriate cases, the success of surgery.

\section{References}

Bake, B., Bjure, J., and Widimsky', J. (1968). The effect of sitting and graded exercise on the distribution of pulmonary blood flow in healthy subjects studied with the ${ }^{133}$ xenon technique. Scandinavian fournal of Clinical and Laboratory Investigation, 22, 99.

Ball, W. C., Jr., Stewart, P. B., Newsham, L. G. S., and Bates, D. V. (1962). Regional pulmonary function studied with xenon ${ }^{133}$. Fournal of Clinical Investigation, 41, 519.

Dawson, A., Kaneko, K., and McGregor, M. (1965). Regional lung function in patients with mitral stenosis studied with xenon ${ }^{133}$ during air and oxygen breathing. Fournal of Clinical Investigation, 44, 999.

Dollery, C. T., and West, J. B. (1960). Regional uptake of radioactive oxygen, carbon monoxide and carbon dioxide in the lungs of patients with mitral stenosis. Circulation Research, 8, 765.

- - - Wilcken, D. E. L., Goodwin, J. F., and Hugh-Jones, P. (I96I). Regional pulmonary blood flow in patients with circulatory shunts. British Heart fournal, 23, 225.

Friedman, W. F., and Braunwald, E. (1966). Alterations in regional pulmonary blood flow in mitral valve disease studied by radioisotope scanning. Circulation, 34, 363.

Hamilton, W. F. (1962). Measurement of the cardiac output. In Handbook of Physiology, section 2. Circulation, vol. I, p. 55I. Ed. by W. F. Hamilton and P. Dow. American Physiological Society, Washington, D.C.

—, Moore, J. W., Kinsman, J. M., and Spurling, R. G. (1932). Studies on the circulation. IV. Further analysis of the injection method and of changes in hemodynamics under physiological and pathological conditions. American fournal of Physiology, 99, 534.

Kunieda, T. (1967). Assessment of impaired pulmonary circulation: effects of gravity on regional pulmonary arterial blood flow in various cardiac and pulmonary diseases studied by external radioisotope scanning. Fapanese Circulation fournal (English ed.), 31, I695.

Oppelt, A., Widimský, J., Staněk, V., Bláha, V., Runczik, I., and Vavrejn, B. (I966). Regional pulmonary function in normals and in disease studied by intravenously injected $\mathrm{Xe}^{133}$. Bulletin de Physio-Pathologie Respiratoire, 2, 653. 
Steiner, S. H., and Quinn, J. M., III (1968). Cardiovascular hemodynamics: determination from the distribution of pulmonary blood flow in seated patients. Fournal of the American Medical Association, 203, 850.

West, J. B. (1962). Regional differences in gas exchange in the lung of erect man. Fournal of Applied Physiology, 17, 893.

- , and Dollery, C. T. (1960). Distribution of blood flow and ventilation-perfusion ratio in the lung, measured with radioactive $\mathrm{CO}_{2}$. Fournal of Applied Physiology, 15, 405.
West, J. B., Dollery, C. T., and Heard, B. E. (I964). Increased vascular resistance in the lower zone of the lung caused by perivascular oedema. Lancet, 2, I8I.

- , and - (1965). Increased pulmonary vascular resistance in the dependent zone of the isolated dog lung caused by perivascular edema. Circulation Research, 17, 191.

Widimský, J., Runczik, I., Vavrejn, B., and Staněk, V. (1965). Determination of regional pulmonary perfusion using $\mathrm{Xe}^{133}$. (In $\mathrm{Czech}$.) Časopis Lékařru Českých, 104, II54. 